\title{
The relationships between selected traits in spring barley using linear and rank correlation coefficients
}

\section{Zastosowanie korelacji liniowej i rangowej do analizy współzależności wybranych cech jęczmienia jarego}

\author{
Anna Tratwal ${ }^{1 *}$, Adrian Cyplik², Jan Bocianowski²
}

\section{Summary}

The objective of this study was to assess the relationships between grain yield, thousand-grain weight and area under the disease progress curve in spring barley grown in South-West Poland by linear Pearson correlation coefficient and Spearman's rank correlation coefficient. The study comprised of 25 spring barley genotypes (five cultivars: Basza, Blask, Antek, Skarb and Rubinek as well as all possible 10 two-way mixtures and 10 three-way mixtures combinations), evaluated at eight environments (two locations in four years) in a randomized complete block design, with four replicates. Grain yield, thousand-grain weight and area under the disease progress curve were measured. The linear and rank correlation coefficients were shown as figures for easier observation of their tendency and significance.

Key words: Pearson's correlation, rank correlation, grain yield, thousand-grain weight, area under the disease progress curve, spring barley

\section{Streszczenie}

Celem badań było zastosowanie współczynników korelacji liniowej Pearsona i rangowej Spearmana do oceny współzależności pomiędzy plonem ziarna, masą tysiąca ziaren oraz AUDPC jęczmienia jarego rosnącego w południowo-zachodniej Polsce. Badanie obejmowało 25 genotypów jęczmienia jarego (pięć odmian: Basza, Blask, Antek, Skarb i Rubinek oraz wszystkie 10 możliwych mieszanek podwójnych i 10 mieszanek potrójnych), analizowanych w ośmiu środowiskach (dwie miejscowości w czterech latach) w doświadczeniach polowych, w układzie bloków losowanych kompletnych, w czterech powtórzeniach. Obliczono plon ziaren, masę tysiąca ziaren i AUDPC. Współczynniki korelacji liniowej i rangowej przedstawiono w postaci wykresów umożliwiających łatwe zaobserwowanie ich kierunku i istotności.

Słowa kluczowe: korelacja Pearsona, korelacja rangowa, plon ziaren, masa tysiąca ziaren, AUDPC, jęczmień jary

\footnotetext{
${ }^{1}$ Instytut Ochrony Roślin - Państwowy Instytut Badawczy

Zakład Monitorowania i Sygnalizacji Agrofagów

Władysława Węgorka 20, 60-318 Poznań

${ }^{2}$ Uniwersytet Przyrodniczy w Poznaniu

Katedra Metod Matematycznych i Statystycznych

Wojska Polskiego 28, 60-637 Poznań

*corresponding author: a.tratwal@iorpib.poznan.pl
} 


\section{Wstęp / Introduction}

W rolnictwie bardzo często zaobserwować można związki między badanymi cechami. Takie obserwacje mogą być bardzo pomocne w podejmowaniu decyzji, co do dalszych prac np. genetyczno-hodowlanych. $Z$ drugiej strony ograniczenie obserwowania tylko jednej $z$ wielu silnie skorelowanych ze sobą cech może przełożyć się na ekonomię prowadzonych doświadczeń. Dlatego ważne jest poznanie współzależności, czy współwystępowania cech, ponieważ pozwala to na określenie charakteru obserwowanych zależności. Najczęściej stosowaną metodą oceny współzależności jest zastosowanie analizy korelacji liniowej Pearsona (Wickiel i Filoda 2012; Niemann i wsp. 2018; Tratwal i wsp. 2018). Alternatywą do współczynnika korelacji Pearsona może być współczynnik korelacji rangowej Spearmana, czyli możliwość zastosowania statystyki pozwalającej na określenie zależności zmiennych losowych w sposób niezmienniczy ze względu na operację rangowania. Współczynnik ten w odróżnieniu od klasycznego współczynnika korelacji prostej mierzy monotoniczną zależność między zmiennymi, a nie tylko liniową. Jest to bardzo istotne szczególnie w ochronie roślin, gdzie ważniejszy jest czasami ranking obiektów, a nie do końca ich wartości liczbowe (Hjältén i Price 1997; Kozak i wsp. 2008; 2010; Skomra i wsp. 2013; Jauker i wsp. 2019). Niewątpliwie cenną zaletą współczynnika korelacji rangowej jest jego większa odporność na obserwacje odstające niż współczynnika korelacji liniowej Pearsona.

Celem niniejszej pracy była ocena współzależności pomiędzy plonem ziaren, masą tysiąca ziaren oraz polem powierzchni wykresu pod krzywą rozwoju choroby (AUDPC) odmian i mieszanek jęczmienia jarego z zastosowaniem współczynników korelacji prostej Pearsona i rangowej Spearmana poprzez: (i) określenie rodzaju/kierunku (dodatnia, ujemna) współzależności, (ii) stwierdzenie czy obserwowana relacja jest statystycznie istotna, oraz (iii) uzyskanie liczbowych miar charakteryzujących relację.

\section{Materiały i metody / Materials and methods}

Ścisłe doświadczenia polowe założone zostały w dwóch miejscowościach: w Hodowli Roślin Smolice Oddział Bąków Sp. z o.o. - Grupa IHAR, województwo opolskie $\left(50^{\circ} 42^{`} \mathrm{~N}, 18^{\circ} 28^{\prime} \mathrm{E}\right)$ i w Zakładzie Doświadczalnym Oceny Odmian Kościelna Wieś, województwo wielkopolskie $\left(51^{\circ} 47^{\prime} \mathrm{N}, 18^{\circ} 00^{\prime} \mathrm{E}\right)$, w ciągu czterech sezonów wegetacyjnych (2010, 2011, 2012 i 2013). Doświadczenia zostały założone w czterech powtórzeniach, w układzie kompletnie losowym na poletkach o powierzchniach: $10 \mathrm{~m}^{2}$ (Bąków) i $16,5 \mathrm{~m}^{2}$ (Kościelna Wieś). Do badań użyto pięć odmian jęczmienia jarego - Basza (Ba), Blask (Bl), Antek (A), Skarb (S) i Rubinek (R) oraz ich 10 mieszanek dwuskładnikowych i 10 kombinacji trójskładnikowych. Udział komponentów mieszanek wynosił $1: 1(\mathrm{Ba} / \mathrm{Bl}, \mathrm{A} / \mathrm{Ba}, \mathrm{Ba} / \mathrm{S}, \mathrm{Ba} / \mathrm{R}, \mathrm{Bl} / \mathrm{A}$, $\mathrm{Bl} / \mathrm{S}, \mathrm{Bl} / \mathrm{R}, \mathrm{A} / \mathrm{S}, \mathrm{A} / \mathrm{R}, \mathrm{S} / \mathrm{R})$ lub $1: 1: 1(\mathrm{~A} / \mathrm{Ba} / \mathrm{Bl}, \mathrm{Ba} / \mathrm{Bl} / \mathrm{S}$, $\mathrm{Ba} / \mathrm{Bl} / \mathrm{R}, \mathrm{Ba} / \mathrm{S} / \mathrm{R}, \mathrm{A} / \mathrm{Bl} / \mathrm{S}, \mathrm{Bl} / \mathrm{A} / \mathrm{R}, \mathrm{A} / \mathrm{R} / \mathrm{S}, \mathrm{Bl} / \mathrm{R} / \mathrm{S}, \mathrm{A} / \mathrm{Ba} / \mathrm{S}$, $\mathrm{A} / \mathrm{Ba} / \mathrm{R})$. W sumie badano 25 genotypów.

Badane genotypy (odmiany oraz ich mieszanki) obserwowano pod kątem plonu ziaren, ciężaru masy tysiąca ziaren - jednego z ważniejszych elementów struktury plonu oraz stopnia porażenia przez mączniaka prawdziwego wyrażonego za pomocą wartości pola powierzchni wykresu pod krzywą rozwoju choroby (area under the disease progress curie - AUDPC) (Shaner i Finney 1977; Finckh i wsp. 1999; Woźniak-Strzembicka i Nadziak 2001; Tratwal i Bocianowski 2014). Przed zbiorem, z każdego obiektu pobierano ręcznie po 100 kłosów, które następnie poddano omłóceniu.

Trójczynnikowa analiza wariancji (ANOVA) została przeprowadzona do weryfikacji hipotez o braku efektów genotypów (odmian i ich mieszanin), miejscowości i lat oraz wszystkich interakcji plonu ziaren, masy tysiąca ziaren i AUDPC. Obliczono wartości średnie dla poszczególnych środowisk i na ich podstawie obliczono i przetestowano współczynniki korelacji liniowej Pearsona oraz rangowej Spearmana pomiędzy obserwowanymi cechami.

\section{Wyniki i dyskusja / Results and discussion}

Wyniki analizy wariancji wskazują na istotne statystycznie $(0,001)$ zróżnicowanie genotypów, miejscowości $i$ lat prowadzenia badań oraz interakcji (genotypy $\times$ miejscowości, genotypy $\times$ lata, miejscowości $\times$ lata, genotypy $\times$ miejscowości $\times$ lata) pod względem wszystkich trzech obserwowanych cech: plonu ziarna, masy tysiąca ziaren i AUDPC. W związku z tym faktem analizę korelacji liniowej i rangowej przeprowadzono na wartościach średnich genotypowych w każdym środowisku (lata i miejscowości) osobno.

Wartości współczynników korelacji liniowej i rangowej pomiędzy obserwowanymi cechami w poszczególnych latach przedstawiono na rysunkach 1. i 2., dla doświadczeń przeprowadzonych odpowiednio, w Bąkowie i Kościelnej Wsi. Wartości istotne statystycznie oznaczono kolorem. W doświadczeniach przeprowadzonych w Bąkowie zaobserwowano równoczesną istotność współczynników korelacji liniowej i rangowej pomiędzy plonem ziaren a MTZ w 2010 roku oraz plonem ziaren i AUDPC w roku 2012 i 2013. Ponadto plon ziaren był istotnie liniowo skorelowany z AUDPC w 2010 roku, przy braku skorelowania rangowego. Świadczy to o silniejszej współzależności proporcjonalnej wartości obserwowanych cech (rys. 1). W doświadczeniach przeprowadzonych w Kościelnej Wsi zaobserwowano istotne skorelowanie na obu poziomach (liniowym i rangowym) plonu ziaren z AUDPC w 2010 i 2013 roku (rys. 2). 

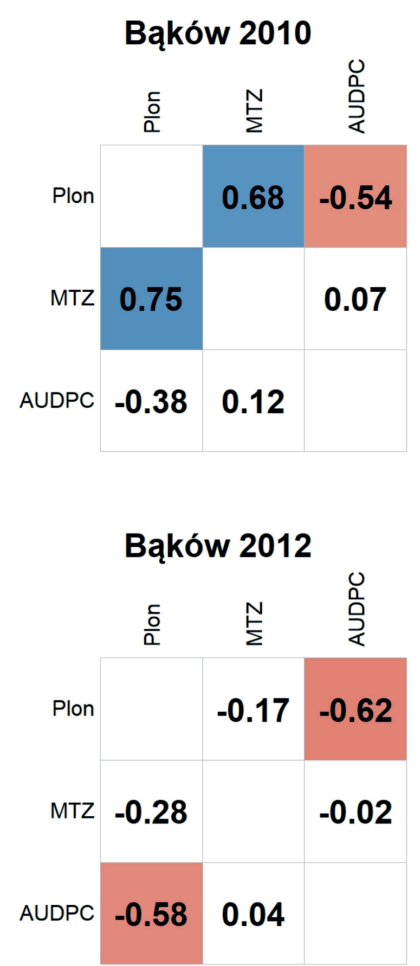

Bąków 2011

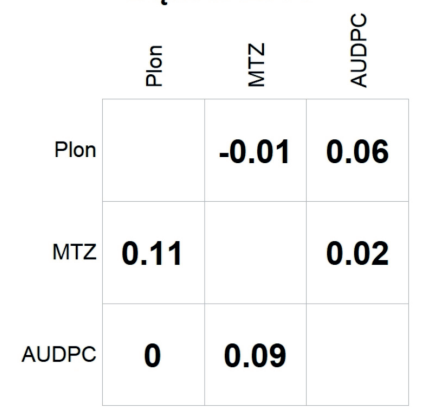

Bąków 2013

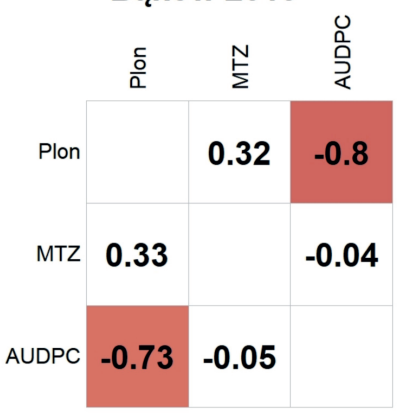

Rys. 1. Współczynniki korelacji liniowej Pearsona (powyżej przekątnej) i rangowej Spearmana (poniżej przekątnej) dla obserwowanych cech badanych w Bąkowie (kolorem oznaczono wartości istotne statystycznie)

Fig. 1. The coefficients of linear Pearson (above diagonal) and Spearman's rank (below diagonal) correlations for the observed traits studied in Bąków (statistically significant correlation coefficients are marked colour)

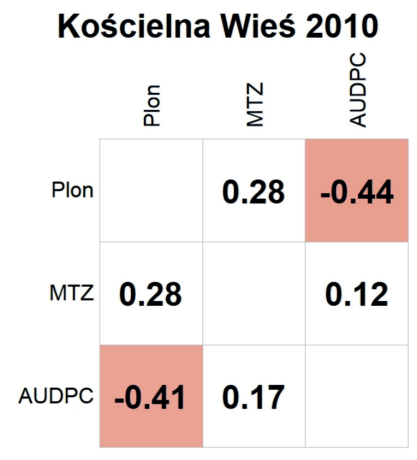

Kościelna Wieś 2012

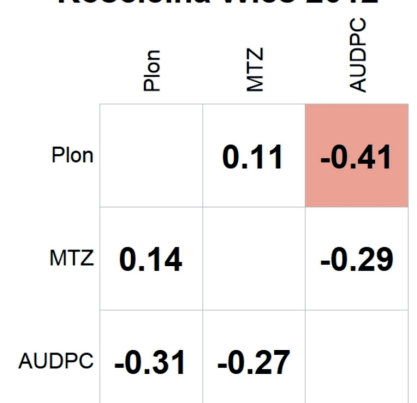

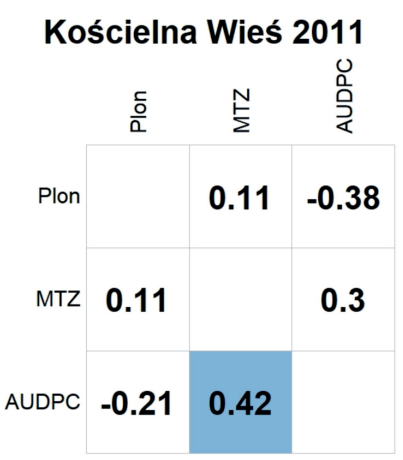

Kościelna Wieś 2013

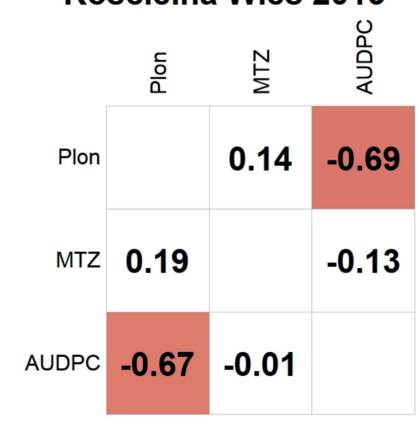

Rys. 2. Współczynniki korelacji liniowej Pearsona (powyżej przekątnej) i rangowej Spearmana (poniżej przekątnej) dla obserwowanych cech badanych w Kościelnej Wsi (kolorem oznaczono wartości istotne statystycznie)

Fig. 2. The coefficients of linear Pearson (above diagonal) and Spearman's rank (below diagonal) correlations for the observed traits studied in Kościelna Wieś (statistically significant correlation coefficients are marked colour) 
Ponadto plon ziaren był liniowo skorelowany z AUDPC w 2012 roku, natomiast MTZ z AUDPC rangowo w 2011 roku (rys. 2). Ta ostatnia istotność, przy braku korelacji liniowej między MTZ i AUDPC, świadczy o braku współzależności proporcjonalnej wartości obu cech w danym roku badań.

Przedstawiony sposób wizualizacji współzależności obserwowanych cech jest bardzo czytelny i efektywny w swej formie. Obok innych form prezentacji wyników (Carr i wsp. 1987; Kozak 2009; Kozak i wsp. 2012; Bocianowski i wsp. 2015) umożliwia szybkie stwierdzenie istotności i kierunku analizowanych relacji między cechami.

$\mathrm{Na}$ szczególną uwagę zasługują ponadto dwie pary współczynników korelacji liniowej Pearsona i rangowej Spearmana pomiędzy plonem ziaren a MTZ w Bąkowie w 2011 roku i MTZ a AUDPC w Bąkowie w 2012 roku (rys. 1). Jakkolwiek współczynniki te nie były istotne statystycznie, to przeciwne ich wartości świadczą o innej współ- zależności obserwowanych wartości i rankingu tych cech, co wymaga baczniejszej analizy w kolejnych doświadczeniach prowadzonych przy warunkach występujących w tych dwu latach prowadzenia badań.

\section{Wnioski / Conclusions}

1. Korelacja liniowa i korelacja rangowa mogą opisywać inną współzależność pomiędzy obserwowanymi cechami. Oba współczynniki warto stosować również dla innych roślin uprawnych i różnych cech - ilościowych i jakościowych.

2. Przedstawiony sposób wizualizacji współczynników korelacji Pearsona i Spearmana pozwala na szybkie i łatwe stwierdzenie istotności i kierunku współzależności.

3. Masa tysiąca ziaren była istotnie skorelowana z AUDPC w czterech z ośmiu rozważanych środowisk.

\section{Literatura / References}

Bocianowski J., Szulc P., Nowosad K. 2015. Parallel coordinate plots of maize traits under different magnesium applications. Journal of Integrative Agriculture 14 (3): 593-597. DOI: 10.1016/S2095-3119(14)60852-2.

Carr D.B., Littlefield R.J., Nicholson W.L., Littlefield J.S. 1987. Scatterplot matrix techniques for large N. Journal of the American Statistical Association 82 (398): 424-436. DOI: 10.1080/01621459.1987.10478445.

Finckh M.R., Gacek E.S., Czembor H.J., Wolfe M.S. 1999. Host frequency and density effects on powdery mildew and yield in mixtures of barley cultivars. Plant Pathology 48 (6): 807-816.

Hjältén J., Price P.W. 1997. Can plants gain protection from herbivory by association with unpalatable neighbours?: A field experiment in a willow-sawfly system. Oikos 78 (2): 317-322. DOI: 10.2307/3546299.

Jauker F., Jauker B., Grass I., Steffan-Dewenter I., Wolters V. 2019. Partitioning wild bee and hoverfly contributions to plant-pollinator network structure in fragmented habitats. Ecology 100 (2): e02569. DOI: 10.1002/ecy.2569.

Kozak M. 2009. What is strong correlation? Teaching Statistics 31 (3): 85-86. DOI: 10.1111/j.1467-9639.2009.00387.x.

Kozak M., Bocianowski J., Rybiński W. 2008. Selection of promising genotypes based on path and cluster analyses. The Journal of Agricultural Science 146 (1): 85-92. DOI: 10.1017/S002185960700754X.

Kozak M., Bocianowski J., Sawkojć S., Wnuk A. 2010. Call for more graphical elements in statistical teaching and consultancy. Biometrical Letters 47 (1): 57-68.

Kozak M., Krzanowski W., Tartanus M. 2012. Use of the correlation coefficient in agricultural sciences: problems, pitfalls and how to deal with them. Anais da Academia Brasileira de Ciências 84 (4): 1147-1156. DOI: 10.1590/S0001-37652012000400029.

Niemann J., Bocianowski J., Wojciechowski A. 2018. Effects of genotype and environment on seed quality traits variability in interspecific cross-derived Brassica lines. Euphytica 214: 193. DOI: 10.1007/s10681-018-2270-8.

Shaner G., Finney R.E. 1977. The effect of nitrogen fertilization on the expression of slow-mildewing resistance in Knox wheat. Phytopathology 67: 1051-1056.

Skomra U., Bocianowski J., Agacka M. 2013. Agro-morphological differentiation between European hop (Humulus lupulus L.) cultivars in relation to their origin. Journal of Food, Agriculture \& Environment 11 (3\&4): 1123-1128.

Tratwal A., Bocianowski J. 2014. Blumeria graminis f. sp. hordei virulence frequency and the powdery mildew incidence on spring barley in the Wielkopolska province. Journal of Plant Protection Research 54 (1): 28-35. DOI: 10.2478/jppr-2014-0005.

Tratwal A., Roik K., Kardasz P. 2018. Plonowanie wybranych odmian pszenżyta ozimego w ramach porejestrowego doświadczalnictwa odmianowego. [Yielding varieties of winter triticale in post registration trials]. Zagadnienia Doradztwa Rolniczego 4 (94): 73-88.

Wickiel G., Filoda G. 2012. Ochrona fungicydowa a obecność objawów fuzariozy kłosów i deoksyniwalenolu w ziarnie pszenicy ozimej orkisz. [Fungicide protection and presence of fuzarium ear symptoms and deoxynivalenol content in the grain of winter spelt]. Progress in Plant Protection/Postępy w Ochronie Roślin 52 (3): 676-679. DOI: 10.14199/ppp-2012-118.

Woźniak-Strzembicka A., Nadziak J. 2001. Powdery mildew Erysiphe graminis f. sp. hordei reduction in mixtures of spring wheat cultivars in comparison with their pure stands. Phytopathologia Polonicum 22: 61-70. 